\title{
Association between serum 25-hidroxyvitamin D concentrations and ultraviolet index in Portuguese older adults: a cross-sectional study
}

Sofia Cardoso ${ }^{1}$, Alejandro Santos ${ }^{1,2}$, Rita S. Guerra ${ }^{1,3}$, Ana S. Sousa ${ }^{1}$, Patrícia Padrão ${ }^{1,4}$, Pedro Moreira ${ }^{1,5,6}$, Cláudia Afonso', Teresa F. Amaral ${ }^{1,3}$ and Nuno Borges ${ }^{1,6^{*}}$ (D)

\begin{abstract}
Background: The older population is a risk group for hypovitaminosis D. The Ultraviolet Index (UVI) can be an indicator of potential for cutaneous synthesis of vitamin D but physiological and other environmental factors also influence vitamin D synthesis and status. Knowledge about vitamin D status in Portuguese older adults is limited. This study aims to explore the association between Ultraviolet Index and serum 25-hidroxyvitamin D3 [25(OH)D] levels accounting for other potential influential factors.

Methods: A cross-sectional study was conducted between December 2015 and June 2016, in 1497 Portuguese older adults ( $\geq 65$ years) within Nutrition UP 65 project. For each participant, serum 25(OH)D was determined and the mean UVI (mUVI) in the respective residence district was calculated for the previous 30 days. Stepwise linear regression analyses were conducted for the following periods of blood collection: between December and June, December and March and April and June. Standardized regression coefficients (S $\beta$ ) and 95\% confidence intervals were calculated.

Results: The median $25(\mathrm{OH}) \mathrm{D}$ concentration was $35.9 \mathrm{nmol} / \mathrm{L}$. The UVI was independently and positively associated with $25(\mathrm{OH}) \mathrm{D}$ in the models for December-June $(\mathrm{S} \beta=0.244,95 \% \mathrm{Cl}: 0.198 ; 0.291, P<0.001)$ and April-June $(\mathrm{S} \beta=0.295$, $95 \%$ Cl: $0.299 ; 0.362, P<0.001)$ and independently and negatively associated in December-March period $(S \beta=-0.149$, 95\% Cl: $-0.211 ;-0.087, P<0.001)$.

Conclusions: In this sample with high vitamin D deficiency frequency, the UVI was a predictor of 25(OH)D levels but the direction of the association varied according to the blood collection period. Our results suggest that accounting for the time of year in future research regarding vitamin status and related public health recommendations may be relevant.
\end{abstract}

Keywords: Vitamin D, Vitamin D deficiency, Older adults, Cutaneous synthesis, 25-hydroxyvitamin D3, Ultraviolet index

\section{Background}

Vitamin D deficiency may be considered a pandemic in Europe and a global public health problem that also entails an economic burden [1, 2]. Older adults, aged 65 years and older are a risk group for vitamin D deficiency [3] and consequences include osteomalacia

\footnotetext{
* Correspondence: nunoborges@fcna.up.pt

'Faculdade de Ciências da Nutrição e Alimentação da Universidade do Porto Rua Dr. Roberto Frias, 4200-465 Porto, Portugal

${ }^{6}$ CINTESIS - Centre for Health Technology and Services Research, Rua Dr. Plácido da Costa, 4200-450 Porto, Portugal

Full list of author information is available at the end of the article
}

and increased risk of muscle weakness, falls and fractures $[4,5]$. Hypovitaminosis D has also been associated with an increased risk of several morbidities including neuropsychiatric, such as dementia [6], and cardiovascular diseases [7].

Sources of vitamin D include solar ultraviolet B (UVB) radiation, diet and supplements. Sun exposure can be considered the main source [4], but at some latitudes and/or seasons, it is not enough to maintain an adequate status and diet or supplements may have a more important role [3]. 
The cutaneous synthesis of vitamin $\mathrm{D}$ is influenced by environmental factors such as UVB radiation available, which is a function of the solar zenith angle that varies with latitude, season and time of day, as well as individual factors such as age, skin pigmentation and sun exposure behaviours [8]. As latitude and age increase, potential to synthesize vitamin $\mathrm{D}$ decreases.

Vitamin D synthesis usually increases from spring to summer and decreases afterwards [4]. This results in a seasonal variation of $25(\mathrm{OH}) \mathrm{D}$ serum concentrations, which reaches its nadir in winter/early spring [1,9]. Researchers have described a "vitamin D winter" referring to the months during which solar UV radiation is not intense enough to allow synthesis $[9,10]$ and occurs at latitudes above approximately $35^{\circ}-40^{\circ} \mathrm{N}[8,11-13]$.

The UV index (UVI) is a parameter that describes the level of UV radiation at the Earth's surface that can cause erythema [14]. Additionally, the UVI can be an indicator of potential for cutaneous synthesis of vitamin D: the higher the UVI the greater the potential [15]. In most studies, sun exposure and UVI are associated with $25(\mathrm{OH}) \mathrm{D}$ concentrations [16-19], but investigation in vivo is still complex. Several studies have also focused on the effect of latitude and season on 25(OH)D. UVI provides more information than latitude by itself, because it's dependent on solar zenith angle and accounts for other variables that affect UV radiation available for synthesis. This study will explore the association of UVI and $25(\mathrm{OH}) \mathrm{D}$ concentrations accounting for the effect of other variables such as sociodemographic, health and anthropometric data, which were not included in previous studies that evaluated sun exposure or just the association between UVI and vitamin $\mathrm{D}$ status.

Current knowledge about the vitamin $\mathrm{D}$ status of elderly in Portugal is limited [20].

In other countries in similar latitudes, such as Spain [21-23] and Italy [24, 25] as well as in Europe, America and Australia more studies have been published in this area $[26,27]$. The investigation of the association between UVI and 25(OH)D was not done in older adults specifically $[17-19,28]$.

Since population ageing is accelerating [29] and given the pleiotropic effects of vitamin D and the possibility in modifying disease risk [9], the study of the determinants of vitamin D status, namely its association with the UVI, could improve knowledge and provide useful information for future research and guidelines that help to face this problem.

The aim of this study was to explore the association between UVI and serum 25-hidroxyvitamin D3 [25(OH)D] levels, considering the effect of other potential influential factors, in Portuguese older adults.

\section{Methods}

\section{Study design and setting}

The present study is a cross-sectional study with a subsample of 1497 older adults ( $\geq 65$ years) from the Nutrition UP 65, whose data collection took place between December 2015 and June 2016. The "Nutrition UP 65 Study - Nutritional Strategies Facing an Ageing Demography" is a cross sectional observational study conducted in Portugal, in a sample of 1500 subjects ( $\geq 65$ years old). The main objectives were to reduce the nutrition inequalities and provide knowledge about nutritional status of this population [20]. The complete description of Nutrition UP 65 can be read elsewhere [20].

Three individuals were excluded from the original sample: one subject presented a serum $25(\mathrm{OH}) \mathrm{D}$ concentration above the toxicity level of $375.0 \mathrm{nmol} / \mathrm{L}$ [9] and two subjects were excluded due to missing data.

All data of this study were obtained within the Nutrition UP 65 except for the UVI and latitude data.

\section{Sampling and recruiting}

A quota sampling approach regarding sex, age, educational level and regional area was implemented to obtain a representative sample of Portuguese older adults. Eligible individuals were Portuguese, with 65 years of age or more. The sample was constituted by communitydwelling and $5 \%$ of institutionalized individuals, according to the previously described proportion [29].

The regional areas used were the ones defined in the Nomenclature of Territorial Units for Statistics (NUTS II): Alentejo, Algarve, Azores, Lisbon Metropolitan Area, Center, Madeira, and North. A random and stratified cluster sampling was applied. In each regional area, three or more town councils with more than 250 inhabitants were randomly selected.

Potential participants were informed about the Nutrition UP 65 and were invited to participate.

\section{Study locations}

In total, 15 districts were selected: 13 districts of mainland Portugal which were Aveiro $\left(40.9^{\circ} \mathrm{N}\right)$, Braga $\left(41.5^{\circ} \mathrm{N}\right)$, Coimbra $\left(40.2^{\circ} \mathrm{N}\right)$, Évora $\left(38.7^{\circ} \mathrm{N}\right)$, Faro $\left(37.1^{\circ} \mathrm{N}\right)$, Leiria $\left(39 .{ }^{\circ} \mathrm{N}\right)$, Lisboa $\left(38.9^{\circ} \mathrm{N}\right)$, Portalegre $\left(39.5^{\circ} \mathrm{N}\right)$, Porto $\left(41.2^{\circ} \mathrm{N}\right)$, Santarém $\left(39.4^{\circ} \mathrm{N}\right)$, Setúbal $\left(38.6^{\circ} \mathrm{N}\right)$, Viana do Castelo $\left(41.7^{\circ} \mathrm{N}\right)$ and Viseu $\left(40.8^{\circ} \mathrm{N}\right)$, in addition to Ponta Delgada from the Azores Archipelago $\left(38.3^{\circ} \mathrm{N}\right)$ and Funchal $\left(32.7^{\circ} \mathrm{N}\right)$ from the Madeira Archipelago.

\section{Ultraviolet index}

The UVI forecast was provided by the Portuguese Institute of Sea and Atmosphere (IPMA), for the studied districts and for the period between November 2015 and July 2016. The forecast corresponded to the daily 
maximum UVI around the solar noon and was obtained by the German Meteorological Service (DWD), whose forecasting has a module structure. The UVI is calculated based on defined values of aerosol optical depth and type and of surface UV albedo. It depends on the solar zenith angle and forecasted ozone columns; it is also adjusted for other variables, such as altitude and cloudiness [30].

\section{Data collected in Nutrition UP 65 Study}

The following information were collected through a structured questionnaire (please see Additional files 1 and 2): cognitive performance; sociodemographic data (sex, age, educational level, professional activity, marital status, residence and household income); lifestyle (current smoking habits, consumption of alcoholic beverages, physical activity and adherence to Mediterranean Diet); skin phenotype; health status and clinical history. Nutritional and vitamin D status were also evaluated. The interviews were carried by previously trained registered nutritionists.

Skin phenotype was self-reported by the participants and classified according to Fitzpatrick (1975) scale that comprises six categories (I-VI) in ascending order of pigmentation [31].

Cognitive performance was assessed by the Portuguese version of the Mini Mental State Examination (MMSE), and categorized as impairment or maintenance, using previously specified cutoff points adjusted for education level [32].

To estimate physical activity level, the short form of the International Physical Activity Questionnaire (IPAQ) was applied [33]. Normal level of physical activity was defined for men and women as $\geq 383$ and $\geq 270 \mathrm{kcal} /$ week, respectively, and low level as $<383$ and $<270 \mathrm{kcal} /$ week, for men and women respectively [34].

Adherence to the Mediterranean diet (MeDi) was assessed by the Portuguese version of the Prevention with Mediterranean Diet tool (PREDIMED) [35]. Additionally, consumption of fish or shellfish $\geq 3$ servings per week was assessed through a specific question included in PREDIMED: "How many servings of fish or shellfish do you consume per week? (1 serving: $100-150 \mathrm{~g}$ of fish or 4-5 units or $200 \mathrm{~g}$ of shellfish)" [36].

Health status was assessed by self-perceived health, which was categorized as follows: very good, good, moderate, bad and very bad [37].

Supplement intake concerning vitamin D and/or multivitamins containing vitamin $\mathrm{D}$ was self-reported by the participants. This includes participants that reported taking drugs containing vitamin $\mathrm{D}$ for osteoporosis treatment.
The Mini Nutritional Assessment ${ }^{\circ}$ - short form tool $\left(\mathrm{MNA}^{\circ}-\mathrm{SF}\right)$ was applied to assess undernutrition status [38, 39].

Detailed anthropometric measurements were performed by the registered nutritionists. Body weight was measured with a calibrated scale (Seca 803, Germany), with a $0.1 \mathrm{~kg}$ resolution, and standing height with a stadiometer (Seca 213, Germany), with a $0.1 \mathrm{~cm}$ resolution, following standard procedures [40]. When necessary, weight was estimated from mid-upper arm and calf circumferences and height was estimated from nondominant hand length, as described elsewhere [20]. Circumferences were obtained with a metal tape (Lufkin, U.S.A., with $0.1 \mathrm{~cm}$ resolution) and hand length with a paquimeter (Fervi Equipment, Italy, with $0.1 \mathrm{~cm}$ resolution). Body mass index (BMI) was calculated using the standard formula [weight $(\mathrm{kg}) / \mathrm{height}^{2}$ (m)]. According to BMI categories, participants were classified as underweight $\left(<18.5 \mathrm{~kg} / \mathrm{m}^{2}\right)$, normal range $(18.5-$ $\left.24.9 \mathrm{~kg} / \mathrm{m}^{2}\right)$, overweight $\left(25-29.9 \mathrm{~kg} / \mathrm{m}^{2}\right)$ and obese $(\geq$ $\left.30 \mathrm{~kg} / \mathrm{m}^{2}\right)$ [41].

Vitamin $\mathrm{D}$ status was assessed by dosing the serum 25(OH)D (nmol/L) concentrations. Blood collection occurred between December 2015 and June 2016, although the time period was not the same for all the districts. Therefore, blood collection occurred only for five or less months in some districts. All samples were analyzed in the same equipment (Cobas Roche) in one central laboratory (General Lab) in Portugal, by electrochemiluminescence assay using Roche Diagnostic Vitamin D Total assay (Roche Diagnostics GmbH, Mannheim, Germany) [42]. The detection limit of this test is $1.2 \mathrm{nmol} / \mathrm{L}[42]$.

\section{Exclusion criteria}

Potential participants presenting any condition that disallowed the collection of venous blood or urine were excluded.

Subjects who had missing data regarding their location were excluded from the original sample.

\section{Statistical analysis}

The mean of daily maximum UVI for the 30 days prior to the respective blood collection date (mUVI) was calculated for each participant. This time period was chosen for several reasons. In the literature, half-life of serum $25(\mathrm{OH}) \mathrm{D}$ has been reported to range from 2 to 3 weeks [43] to 2 months [44]. Also, the lag-time between a change in monthly UV dose and the corresponding change in 25(OH)D levels has been reported to range from 4 to 8 weeks $[17,45,46]$.

The variable serum $25(\mathrm{OH}) \mathrm{D}$ concentrations $(\mathrm{nmol} / \mathrm{L})$ was treated as a continuous variable. Mean latitudes of the studied districts were calculated based on the participants' postal code. 
Data in descriptive statistics are presented as median and first and third quartile (Q1 and Q3) of 25(OH)D concentrations (due to a non-normal distribution) for each potential influential variable of serum 25(OH)D. For presentation of the results, variables were categorized as follows: age (65-69, 70-74, 75-79 and $\geq 80$ years old), educational level (0,1-4, 5-12 and $\geq 13$ years of school completed), marital status (not married or married), household income $(<500,500-999, \geq 1000$ $€ /$ month and does not know or does not declare), skin phenotype (I-II, III-IV and V-VI), smoking habits (yes if at least 1 cigarette/month and no if $<1$ cigarette/month) alcoholic beverages consumption (none, moderate if 1 drink/day for women and 1-2 drinks/day for men [47], and heavy if $\geq 2$ drinks/day for women and $\geq 3$ drinks/ day for men), undernutrition status by $\mathrm{MNA}^{\oplus}-\mathrm{SF}$ (without undernutrition and undernourished/at risk of undernutrition) and period of blood collection (DecemberMarch which comprises late autumn, winter and early spring, and April-June which comprises spring and early summer). This last categorization was also adopted by other authors [1, 48, 49].

In descriptive statistics UVI was treated as a categorical variable and it was categorized as low (1-2), moderate (3-5), high (6-7) and very high (8-10) [50].

According to $25(\mathrm{OH}) \mathrm{D}$ concentrations, participants were compared for several sociodemographic, lifestyle, health, nutritional and environmental characteristics. For the dichotomous variables, statistical significance of differences in serum $25(\mathrm{OH}) \mathrm{D}$ concentrations was assessed with the Mann-Whitney test. For variables with more than two categories, differences were tested using Kruskal-Wallis test and Mann-Whitney test with Bonferroni correction.

To illustrate the variation of serum $25(\mathrm{OH}) \mathrm{D}$ concentrations and mUVI, during the blood collection period, a chart was plotted. For each month, the median, Q1 and Q3 of 25(OH)D concentrations, as well as the mean and standard deviation (SD) of mUVI of the participants were calculated.

Mann-Whitney test with Bonferroni correction was performed to test statistical significance of differences in serum 25(OH)D concentrations between consecutive months.

The association between serum $25(\mathrm{OH}) \mathrm{D}$ concentrations and mUVI was explored by multiple linear regression analysis using the stepwise method. Due to a non-normal distribution of the dependent variable, $25(\mathrm{OH}) \mathrm{D}$, a logarithm (log base 10$)$ transformation was conducted $\left[\log _{10} 25(\mathrm{OH}) \mathrm{D}\right]$. The following independent variables were included: mUVI (continuous), sex (dichotomous), age (continuous), education (categorical), professional activity (dichotomous), marital status (dichotomous), residence (dichotomous), household income (categorical), skin phenotype (categorical), cognitive performance (continuous), smoking habits (dichotomous), alcoholic beverages consumption (categorical), adherence to MeDi (continuous), fish or shellfish consumption $\geq 3$ times/week (dichotomous), self-perceived health (categorical), supplement intake (dichotomous), undernutrition status by $\mathrm{MNA}^{\ominus}$-SF (continuous) and BMI (continuous). Cognitive performance, measured by MMSE score, and undernutrition status, assessed by $\mathrm{MNA}^{\oplus}$-SF score, were exponentially transformed before computing the model to achieve a normal distribution. Independent variables were chosen based on previous studies. Three multiple linear regression analyses were conducted using the same method. A regression analysis was conducted for the entire blood collection period, between December and June (Dec-Jun). Additionally, two regression analyses stratified by period of blood collection were conducted: between December and March (Dec-Mar) and between April and June (Apr-Jun).

For the results of stepwise linear regression analyses, standardized regression coefficients $(\mathrm{s} \beta)$ and the respective 95\% Confidence Interval (95\% CI) are presented. Standardized regression coefficients were used to allow comparisons between explanatory variables [51].

\section{Results \\ Descriptive statistics}

Median 25(OH)D concentrations and other descriptive data, by potential influential factors of $25(\mathrm{OH}) \mathrm{D}$, are shown in Table 1.

In this population of older adults, the median (Q1; Q3) of 25(OH)D concentration was $35.9 \mathrm{nmol} / \mathrm{L}$ (21.90; 57.35).

Analyzing median 25(OH)D concentrations for each variable (Table 1), these were significantly lower in women than in men, as well as in participants with $\geq 80$ years old, no education, institutionalized, not professionally active, not married, with a household income of $<500 € /$ month, cognitively impaired, with no alcoholic beverages consumption, with low physical activity level, with low adherence to $\mathrm{MeDi}$, that rated their health status as bad or very bad, without supplement intake, undernourished or at risk of undernutrition and whose blood was collected in December-March. Obese individuals had lower $25(\mathrm{OH})$ concentrations than subjects in the normal range or overweight (Mann-Whitney test $P<0.001$ )

Concentrations of serum 25(OH)D increased significantly across ascending mUVI categories (Mann-Whitney test after Bonferroni correction $P<0.001$ ), except for the low and moderate categories (Mann-Whitney test after Bonferroni correction $P>0.008)$. 
Table 1 Median 25(OH)D concentrations ( $\mathrm{nmol} / \mathrm{L}$ ) of the sample, by potential influential factors

\begin{tabular}{llll}
\hline Variable & $n$ & Median $(\mathrm{Q} 1 ; \mathrm{Q} 3)$ & $P$-value \\
\hline Sex & & & $<0.001$ \\
$\quad$ Female & 872 & $32.95(19.45 ; 52.88)$ & \\
$\quad$ Male & 625 & $45.58(26.10 ; 61.80)$ &
\end{tabular}

Age (years)$$
\text { 65-69 }
$$

70-74

75-79

$\geq 80$

NUTS ॥

North

Center

Lisbon Metropolitan Area

Alentejo

Algarve

Madeira

Azores

Education (years)

0

$1-4$

$5-12$

$\geq 13$

Professionally active

No

Yes

Marital status

Single, divorced or widowed

Married or common-law marriage

Residence

Home

Institution

Household income $(€)$

$$
<500
$$

500-999

$\geq 1000$

Doesn't declare/Doesn't know

Skin phenotype

$$
\begin{aligned}
& \text { I+ II } \\
& I I+I V \\
& V+V I
\end{aligned}
$$

Cognitive performance (MMSE)

\section{Maintenance}

Impairement

$<0.001$

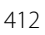

372

319

394

468

391

383

136

65

30

24

$44.35(29.95 ; 63.98)$

38.35 (25.60; 58.68)

34.20 (20.20; 58.30)

24.85 (14.50; 44.83)

$35.50(20.35 ; 58.40)$

31.50 (17.20; 50.80)

$42.20(28.80 ; 62.30)$

$30.60(22.15 ; 51.48)$

$36.30(20.75 ; 55.20)$

54.45 (39.23; 74.85)

$42.75(21.10 ; 59.88)$

212

$23.80(13.53 ; 35.20)$

1029

$36.90(21.95 ; 57.10)$

188

68

44.95 (29.18; 65.63)

$46.30(31.18 ; 74.88)$

$1462 \quad 35.75(21.58 ; 57.15)$

30

$46.55(29.33 ; 65.60)$

796

29.85 (17.30; 48.20)

$43.40(28.63 ; 64.10)$

$1425 \quad 36.80(22.35 \cdot 58.00)$

72

$17.90(10.23 ; 38.28)$

248

305

174

770

29.95 (17.48; 44.93)

$36.40(24.15 ; 58.70)$

$48.55(33.65 ; 69.88)$

35.30 (19.90; 56.95)

$305 \quad 37.30(24.85 ; 51.90)$

$110936.30(21.30 ; 59.15)$

$80 \quad 30.00(18.95 ; 46.33)$

$1398 \quad 36.50(22.10 ; 58.43)$

$99 \quad 28.10(13.60 ; 45.90)$
$<0.001$

$<0.001$

$<0.001$

$<0.001$

0.064

$<0.001$
Table 1 Median 25(OH)D concentrations (nmol/L) of the sample, by potential influential factors (Continued)

\begin{tabular}{lllr}
\hline Variable & $n$ & Median (Q1; Q3) & $P$-value \\
\hline Smoking habits & & & 0.850 \\
No & 1429 & $35.90(21.75 ; 57.40)$ & \\
Yes & 68 & $36.15(22.65 ; 51.83)$ &
\end{tabular}

Alcoholic beverages consumption

$<0.001$

Does not drink

$952 \quad 32.95(20.33 ; 51.78)$

Moderate

$388 \quad 43.85(24.33 ; 64.63)$

Heavy

Physical activity (IPAC)

Normal

Low

Adherence to Mediterranean diet (PREDIMED)

Low

High

$15541.80(27.80 ; 61.10)$

$123438.30(23.60 ; 59.00)$

$261 \quad 25.60(14.85 ; 47.75)$

0.001

$84934.20(20.40 ; 54.70)$

$648 \quad 39.05(23.63 ; 60.30)$

Fish/shellfish consumption

$\geq 3$ servings/week

No

Yes

Self-perceived health

Very good

Good

Moderate

Bad

Very bad

Supplement intake

No

Yes

Undernutrition status (MNA-SF)

Without undernutrition

Undernourished/at risk

of undernutrition

Body mass index

Underweight

Normal range

Overweight

Obese

mUVI categories

Low

Moderate

High

Very high

Period of blood collection

December - March

April - June

$n$ number of subjects (does not always ad up to 1497 because of missing data). Q1: first quartile; Q3: third quartile

$P$-value for Mann-Whitney dichotomous variables or Kruskal-Wallis test for variables with $>2$ categories

${ }^{\mathrm{a}} \mathrm{Q} 3$ was not possible to calculate
$3723.00(23.70 ; 60.45)$

$112535.50(21.00 ; 56.30)$

$<0.001$

$6944.30(32.50 ; 64.20)$

$409 \quad 42.20(24.40 ; 62.60)$

$730 \quad 35.30(22.30 ; 57.10)$

$232 \quad 28.30(15.50 ; 44.23)$

$53 \quad 25.50(17.25 ; 47.55)$

$136934.90(20.95 ; 54.85)$

$128 \quad 54.55(35.53 ; 82.78)$

$1256 \quad 37.50(22.50 ; 58.88)$

$241 \quad 29.00(16.90 ; 47.65)$

$<0.001$

$3 \quad 38.20\left(21.90 ;^{a}\right)$

$660 \quad 38.55(23.53 ; 60.60)$

$582 \quad 31.20(19.10 ; 50.10)$

$<0.001$

$570 \quad 30.05(17.10 ; 48.50)$

$518 \quad 32.30(19.88 ; 50.88)$

$22245.55(29.88 ; 65.00)$

$187 \quad 52.00(39.00 ; 69.80)$
$248 \quad 42.75(23.25 ; 65.38)$

\section{.001} 001 


\section{Variation of mUVI and 25(OH)D by month of blood collection}

The variation of mUVI and $25(\mathrm{OH}) \mathrm{D}$ concentrations during the blood collection period is shown in Fig. 1, where the mean of mUVI for all districts analysed in each month and the correspondent median 25(OH)D concentrations are presented. The mean of mUVI had its minimum in January (1.2) and increased until June, when it reached its peak (7.9). The mUVI was $>3$ between April and June. Although 25(OH)D concentrations increased from December to January and median concentration reached its nadir in March $(23.85 \mathrm{nmol} / \mathrm{L})$, differences were not statistically significant between consecutive months within this

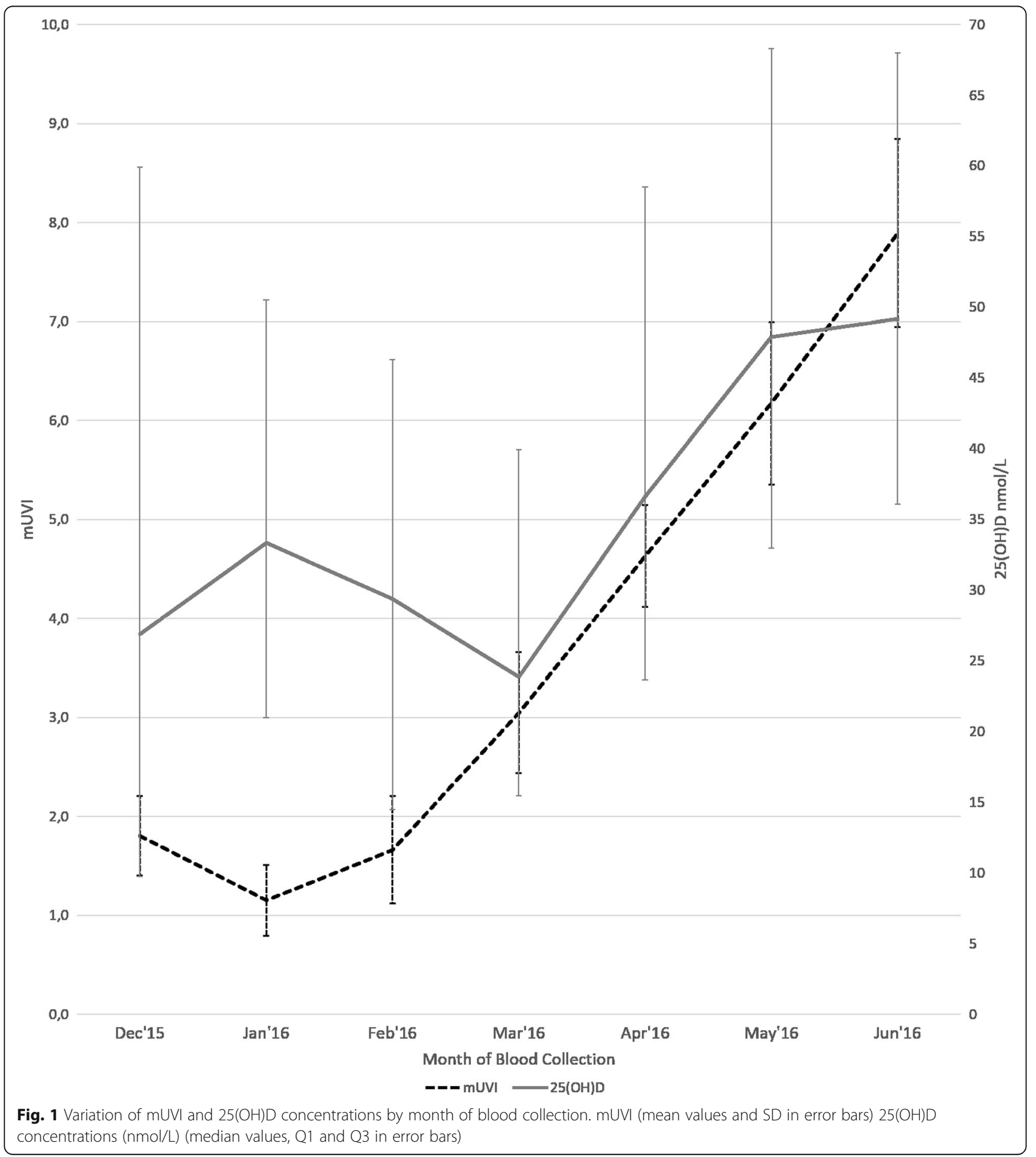


period. After March 25(OH)D concentrations increased significantly between consecutive months until May (all $P<0.001$ ), when the median concentration was not significantly different from June $(49.2 \mathrm{nmol} / \mathrm{L})$.

\section{Multiple linear regression analysis for the entire blood collection period}

The model for Dec-June explained $28 \%$ of the variance in $25(\mathrm{OH}) \mathrm{D}$ concentrations (adjusted $\mathrm{R}^{2}=0.28$ ). Of all the continuous variables, mUVI had the highest effect on $25(\mathrm{OH}) \mathrm{D}$ concentrations $(\mathrm{S} \beta=0.244)$.

In the model for Dec-Mar, mUVI was negatively associated with $25(\mathrm{OH}) \mathrm{D}$ concentrations $(\mathrm{S} \beta=-0.149)$, contrarily to the models for Apr-Jun $(S \beta=0.295)$ and Dec-June $(S \beta=0.244)$. Comparing models for Dec-Mar and Apr-Jun, some of the independent variables associated with $25(\mathrm{OH}) \mathrm{D}$ in the models were different. The following variables were associated in all three models: mUVI, age, supplement intake, undernutrition status and BMI. Both stratified models explained approximately $23 \%$ of the variance in $25(\mathrm{OH}) \mathrm{D}$ concentrations (Dec-Mar: adjusted $\mathrm{R}^{2}=0.229$; Apr-Jun: adjusted: $\mathrm{R}^{2}=0.232$ ).

In the multivariable model for Dec-Jun, an increase of 1 unit in mUVI was associated with an increase in $25(\mathrm{OH}) \mathrm{D}$ of $1.1 \mathrm{nmol} / \mathrm{L}$ (regression coefficient $=0.030$ ). In multivariable the model for Apr-Jun an increase of 1 unit in mUVI was associated with an increase in $25(\mathrm{OH}) \mathrm{D}$ of $1.1 \mathrm{nmol} / \mathrm{L}$ (regression coefficient $=0.049$ ).

\section{Discussion}

In our cross-sectional study of Portuguese older adults, the median 25(OH)D concentration was $35.90 \mathrm{nmol} / \mathrm{L}$.

In the Survey in Europe on Nutrition and the Elderly: A Concerted Action (EURONUT-SENECA study) the mean 25(OH)D levels ranged from 20 to $30 \mathrm{nmol} / \mathrm{L}$ in Southern European centers [52]. Comparisons should be taken cautiously due to discrepancies in latitude of the sample, ethnicity and season of blood collection [53].

In agreement with previous reports, the observed differences in 25(OH)D levels in our sample (Table 1), were as expected for the following variables: sex [53], age [53], physical activity [54, 55], BMI [48, 49], residence $[56,57]$ and supplement intake $[23,48]$.

The serum 25(OH)D concentrations increased significantly across ascending mUVI categories above moderate, which is in line with previous works [49,54]. As expected, 25(OH)D concentrations were lower in Dec-Mar (late autumn-early spring) than in Apr-Jun (spring-early summer) which reflects the seasonal variation reported for 25(OH)D levels $[48,58]$ (Table 1$)$.

Figure 1 showed a fluctuation of $25(\mathrm{OH}) \mathrm{D}$ concentrations and mUVI along the blood collection period. The variation of $25(\mathrm{OH}) \mathrm{D}$ from December to June was similar
Table 2 Factors associated with $25(\mathrm{OH}) \mathrm{D}(\mathrm{nmol} / \mathrm{L})$ by multiple linear regression for the period between December-June $(n=1486)$

\begin{tabular}{lll}
\hline Independent variables & $\mathrm{S} \beta(95 \% \mathrm{Cl})$ & $P$ value \\
\hline $\mathrm{mUVI}$ & $0.244(0.198 ; 0.291)$ & $<0.001$ \\
Age (years) & $-0.135(-0.184 ;-0.086)$ & $<0.001$ \\
Residence & $-0.064(-0.110 ;-0.019)$ & 0.005
\end{tabular}

(home - 0; institution - 1)

Education (years) ${ }^{\text {b }}$

0

$5-12$

$-0.060(-0.106 ;-0.014) \quad 0.010$

$0.052(0.007 ; 0.096) \quad 0.022$

Marital status

(not married - 0; married - 1)

$0.089(0.042 ; 0.137) \quad<0.001$

Household income $(€ / \text { month })^{c}$

\begin{tabular}{|c|c|c|}
\hline 500-999 & $0.056(0.011 ; 0.101)$ & 0.015 \\
\hline$\geq 1000$ & $0.099(0.052 ; 0.145)$ & $<0.001$ \\
\hline hysical activity (normal - 0; low -1$)^{a}$ & $-0.078(-0.124 ;-0.033)$ & 0.001 \\
\hline $\begin{array}{l}\text { oholic beverages } \\
\text { רsumption - moderate }\end{array}$ & $0.054(0.011 ; 0.098)$ & 0.015 \\
\hline -perceived health - bad ${ }^{\mathrm{e}}$ & $-0.051(-0.096 ;-0.007)$ & 0.024 \\
\hline ipplement intake (no - 0; yes - 1) ${ }^{\mathrm{a}}$ & $0.202(0.158 ; 0.245)$ & $<0.001$ \\
\hline ndernutrition status (MNA ${ }^{\oplus}$-SF score) & $0.070(0.025 ; 0.115)$ & 0.002 \\
\hline
\end{tabular}

BMI $\left(\mathrm{kg} / \mathrm{m}^{2}\right) \quad-0.123(-0.168 ;-0.079)<0.001$

$\mathrm{Cl}$ confidence interval, $M N A^{\oplus}$-SF Mini Nutritional Assessment ${ }^{\oplus}$ - Short Form, $S \beta$ Standardized regression coefficient

The model included only 1486 subjects because of missing data

aFor the dichotomous variables, reference categories were coded as " 0 "

"Reference: "1-4 years"

"Reference: "Does not know or does not declare"

dReference: "None"

eReference: "Moderate"

to previous studies, which have also found a minimum in March (or late winter/early spring) $[59,60]$ and an increase in spring and summer $[1,48,61]$. Similarly to another Portuguese work, frequency of sufficiency of vitamin $\mathrm{D}(\geq 75 \mathrm{nmol} / \mathrm{L})$ was below $50 \%$ in every month [62]. It was noticeable that although mUVI started to increase in February, the rise of $25(\mathrm{OH}) \mathrm{D}$ concentrations only began in April, when mUVI was $>3$. This is in line with statements that UVI $<3$ does not trigger adequate synthesis of vitamin $\mathrm{D}[63,64]$. At latitudes $>37^{\circ} \mathrm{N}$, from November through February, the amount of UV radiation is usually not enough to initiate cutaneous synthesis [58]. O'Neill et al. (2016) also found that the UV threshold for adequate synthesis was only reached in mid-March, in European countries [59]. There might also have been a lag-time between a change on monthly UVI and the corresponding change in $25(\mathrm{OH}) \mathrm{D}$ levels, which has been reported to range from 4 to 8 weeks $[17,45,46]$. This lag-time may be linked to synthesis and half-life of vitamin $\mathrm{D}$ [65]. The decrease in $25(\mathrm{OH}) \mathrm{D}$ between January and March might have been influenced by the fact that UVI was not intense enough to trigger vitamin D 
synthesis [63, 64], and/or exposure was not likely to occur due to low temperatures, limited hours of sunshine and/ or individual factors such as clothing [66-68].

The model for Dec-Jun (Table 2) explained 28\% of the variance in $25(\mathrm{OH}) \mathrm{D}$ concentrations. [48, 54]. Associations between the independent variables and $25(\mathrm{OH}) \mathrm{D}$ were expected, according to previous research in middle aged and older populations, for: age $[49,54]$, household income [69], education [49], residence [70, 71], alcoholic beverages consumption $[53,72]$ physical activity $[55,73]$ self-perceived health [54], supplement intake [55, 74] and BMI $[53,54]$.

Most studies that measured sun exposure or UV radiation availability found these were predictors of $25(\mathrm{OH}) \mathrm{D}$ concentrations $[23,49,54]$. The present study did not measure sun exposure, but used UVI as an indicator of potential for synthesis of vitamin D. The fact that mUVI was a predictor of $25(\mathrm{OH}) \mathrm{D}$ levels and that there was a positive association between the two is in line with other works that investigated the association between UVI and 25(OH)D levels [17-19]. However, Greer et al. (2013) found no correlation between the two variables, presumably to low sun exposure of the sample [28]. The four previous studies which have used mUVI and $25(\mathrm{OH}) \mathrm{D}$ concentrations did not perform an analysis separated in two seasons as was ran in this study [17-19, 28].

Undernutrition status, as measured by $\mathrm{MNA}^{\circ}$-SF score, was positively associated with $25(\mathrm{OH}) \mathrm{D}$. A lower MNA ${ }^{\circ}$ SF score can be related to a decline in food intake and impaired mobility [39], which could discourage sun exposure and has been associated with vitamin D deficiency $[56,75]$.

Skin phenotype was not associated with 25(OH)D in the model, which occurred in some [76] but not all of the previous studies $[49,70]$. This could have been influenced by the relative narrow range of skin types in our sample.

The majority of the previous studies concluded that dietary vitamin D intake $[48,49,72]$ and fatty fish consumption [77] were predictors of $25(\mathrm{OH}) \mathrm{D}$ concentrations, which were not possible to estimate in our study. However, fish and shellfish consumption $\geq 3$ servings/ week and adherence to MeDi were not associated in the final model. The lack of discrimination between lean and fatty fish, inadequacy of their servings and the absence of questions linked to food with a high vitamin D content might have contributed to the absence of association found for these variables.

Stratification by period of blood collection resulted in models with different predictors of 25(OH)D and opposite associations between UVI and 25(OH)D (Tables 3 and 4).

In the model for Dec-Mar, mUVI was inversely associated with $25(\mathrm{OH}) \mathrm{D}$. This association was expected because, as shown in Fig. 1, between Dec-Mar
Table 3 Factors associated with $25(\mathrm{OH}) \mathrm{D}$ by multiple linear regression for the period between December-March $(n=802)$

\begin{tabular}{lll}
\hline $\begin{array}{l}\text { December - March } \\
\text { Independent variables }\end{array}$ & $S \beta(95 \% \mathrm{Cl})$ & $P$-value \\
\hline mUVI & $-0.149(-0.211 ;-0.087)$ & $<0.001$ \\
Age (years) & $-0.210(-0.276 ;-0.146)$ & $<0.001$ \\
Residence & $-0.104(-0.169 ;-0.041)$ & 0.001 \\
Household income $(€ /$ month) - $\geq 1000$ & $0.147(0.082 ; 0.211)$ & $<0.001$ \\
Household income ( $€ /$ month) - 500-999 & $0.069(0.006 ; 0.132)$ & 0.032 \\
Alcoholic beverages consumption - & $0.070(0.009 ; 0.132)$ & 0.025 \\
Moderate & & \\
Self-perceived health - Bad & $-0.082(-0.144 ;-0.020)$ & 0.010 \\
Supplement intake & $0.196(0.133 ; 0.256)$ & $<0.001$ \\
Undernutrition status (MNA-SF score) & $0.097(0.034 ; 0.159)$ & 0.003 \\
BMI (kg/m²) & $-0.164(-0.226 ;-0.102)$ & $<0.001$
\end{tabular}

$\mathrm{Cl}$ confidence interval, $M N A^{\oplus}$-SF Mini Nutritional Assessment ${ }^{\oplus}$ Short Form, $S \beta$ Standardized regression coefficient

25(OH)D declined despite mUVI was rising. Factors that have been previously discussed for Fig. 1 and were observed in other studies could have contributed to this negative association [66, 67, 78]. The model for Dec-Jun showed a smaller effect of mUVI upon $25(\mathrm{OH}) \mathrm{D}$ concentrations than the model for Apr-Jun. This difference could be explained by the lack of effect of mUVI during the Dec-Mar period, in which the average mUVI values are below the threshold for vitamin D synthesis. Nevertheless, we considered this model for comparison with other published studies.

The present study shows that given the Portuguese latitudes, UV may not be high enough to trigger vitamin D synthesis between late autumn and early spring [8, 11-13]. During this period individuals may have to rely on their vitamin D reserves, which may not last all "vitamin D winter", on diet and on supplements [79].

Table 4 Factors associated with 25(OH)D by multiple linear regression for the period between April-June $(n=683)$

\begin{tabular}{lll}
\hline April-June $(\mathrm{n}=683)$ & $\mathrm{S} \beta(95 \% \mathrm{Cl})$ & $P$-value \\
Independent variables & $0.295(0.229 ; 0.362)$ & $<0.001$ \\
\hline $\mathrm{mUVI}$ & $-0.092(-0.163 ;-0.022)$ & 0.010 \\
Age (years) & $-0.078(-0.148 ;-0.010)$ & 0.025 \\
Education (years) - zero & $0.140(0.072 ; 0.209)$ & $<0.001$ \\
Marital Status & $-0.079(-0.145 ;-0.013)$ & 0.019 \\
Skin phenotype - V + VI & $0.086(0.016 ; 0.156)$ & 0.016 \\
Cognitive performance (MMSE score) & $-0.102(-0.172 ;-0.034)$ & 0.004 \\
Physical Activity - Low & $0.246(0.181 ; 0.315)$ & $<0.001$ \\
Supplement intake & $0.076(0.008 ; 0.145)$ & 0.030 \\
Undernutrition status (MNA-SF score) & $-0.117(-0.185 ;-0.050)$ & 0.001 \\
\hline BMI (kg/m $\left.{ }^{2}\right)$ &
\end{tabular}

$\mathrm{Cl}$ confidence interval, $M N A^{\oplus}$-SF Mini Nutritional Assessment ${ }^{\oplus}$ Short Form, $S \beta$ Standardized regression coefficient 
Since vitamin D ingestion may not be adequate, supplementation may be advisable in older adults $[63,68]$.

In the model for Apr-Jun, mUVI was positively associated with $25(\mathrm{OH}) \mathrm{D}$, which is in line with previous studies [17-19]. In these months sun exposure is more likely to occur [23] and it was expected that the higher UVI ( $\mathrm{mUVI}>3$ ) would promote synthesis and contribute to the higher 25(OH)D concentrations, comparatively to Dec-Mar [63, 80]. The observation of low $25(\mathrm{OH}) \mathrm{D}$ concentrations despite UVI $>3$ is in line with reports of high levels of deficiency even in regions with high UVI, particularly in risk groups as the elderly $[67,81]$. Additionally, older people synthesize vitamin D less efficiently [63] and tend to avoid sun exposure even when temperatures are high [21]. The widespread public health advice on skin protection can also contribute to limited sun exposure [3].

The fact that different predictors have been selected in both stratified models and UVI associations were opposite may also be related with the characteristics of the different groups of participants.

Nevertheless, UV exposure can increase 25(OH)D in older adults, depending on the season [82, 83]. Moreover, sun exposure during summer is a major determinant for vitamin D stores [84]. Therefore, even though deficiency was frequent in this and other works, optimizing vitamin $\mathrm{D}$ stores is still important to maintain or at least to minimize the decline of vitamin D status during winter for as long as possible [15, 53].

As far as we are concerned, this is the first study to explore the relationship between UVI and 25(OH)D in older people in Portugal. Also, only four studies could be found to explore this relationship in other countries $[17-19,28]$. The main strengths of this study include the large sample size, the nationwide coverage and the fact that the assay, equipment and laboratory of $25(\mathrm{OH}) \mathrm{D}$ quantification were the same, which decreased the variability existent in several works [1]. Moreover, the model for Dec-Jun explained $28 \%$ of the variance in $25(\mathrm{OH}) \mathrm{D}$ concentrations, which was in line with the results from previous studies that included sun exposure, diet and genetic factors as potential predictors of $25(\mathrm{OH}) \mathrm{D}$ concentrations. The use of UVI as an indicator of potential for vitamin D synthesis, instead of latitude and season, constitutes another strength of this study, since UVI accounts for latitude, season and intensity of UV that reaches the Earth adjusted for nebulosity and ozone absorption [79].

\section{Limitations}

The UVI is based on the UV spectrum for erythema, which some authors argue that diverges from the vitamin D action spectrum [85].
It was not possible to estimate sun exposure from the collected data and UVI may indicate only the potential to synthesize vitamin D. Various factors that were not possible to assess may have interfered in this potential, including sun exposure behaviors (such as sunscreen use, clothing, duration and location of exposure) and ambient factors such as pollution [86]. Genetic factors, interindividual variability, diet, certain medications, chronic kidney conditions, including renal failure, and other diseases may also have affected 25(OH)D synthesis and/or concentrations of our sample but is effect was not accounted for.

The measured 25(OH)D concentrations may not reflect the long-term levels of the population [81]. The fact that this is a cross-sectional observational study does not allow the establishment of causal relationships. The sample of our study was not randomly selected and a participation bias might have existed, which impair the generalization of our results to the population.

\section{Conclusions}

This study shows that the association between UVI and vitamin D may be different depending on the time of the year and thus, future research and recommendations about sensible sun exposure and vitamin D status should take this into account. Diet and supplements may be more important D during months when UVI and sun exposure are low/insufficient and should be reinforced accordingly.

\section{Additional files}

Additional file 1: Portuguese questionnaire applied to participants. File containing the full questionnaire that was applied to all participants. (PDF $346 \mathrm{~kb}$ )

Additional file 2: An English translation of the Portuguese questionnaire applied to participants. File containing the translated questionnaire that was applied to all participants. (PDF $1005 \mathrm{~kb}$ )

\section{Abbreviations}

25(OH)D: 25-hydroxitamin D; BMI: Body Mass Index; EURONUT-SENECA: Survey in Europe on Nutrition and the Elderly: A Concerted Action; IOM: Institute of Medicine; IPAC: International Physical Activity Questionnaire; MeDi: Mediterranean diet; MET: Metabolic equivalent task; MMSE: Mini Mental State Examination; MNA ${ }^{\oplus}$ SF: Mini Nutritional Assessment Short Form; mUVI: Mean Ultraviolet Index; NUTS II: Nomenclature of Territorial Units for Statistics II; PREDIMED: Prevention with Mediterranean Diet tool; UVB: Ultraviolet B; UVI: Ultraviolet Index

\section{Acknowledgements}

The authors would like to acknowledge the Nutrition UP 65 team. The present project was granted by the Public Health Initiatives Programme (PT06), financed by EEA Grants Financial Mechanism 2009-2014.

\section{Funding}

Nutritional Strategies Facing an Older Demographic: The Nutrition UP 65 Study was financed, in $85 \%$ by Iceland, Liechtenstein and Norway through European Economic Area Grants and in 15\% by Faculty of Nutrition and Food Science of University of Porto. The European Economic Area Grants are managed by Administração Central do Sistema de Saúde through the Programa Iniciativas em Saúde Pública. 


\section{Availability of data and materials}

The datasets used and/or analyzed during the current study are available from the corresponding author on reasonable request.

\section{Authors' contributions}

SC, AS and NB designed the research. SC performed UVI and latitude data collection. SC, RSG, ASS, TFA and NB analyzed data. SC and NB wrote the manuscript. All the authors contributed to the final draft and approved the final version.

\section{Ethics approval and consent to participate}

The Nutrition UP 65 research was performed according to the guidelines established by the Declaration of Helsinki, and the study protocol was approved by the Ethics Committee of the department of Ciências Sociais e Saúde (Social Sciences and Health) from the Faculdade de Medicina da Universidade do Porto (PCEDCSS - FMUP 15/2015) and by the Portuguese National Commission of Data Protection (9427/2015) [20].

An informed consent form was signed in case of acceptance.

\section{Consent for publication}

Not applicable

\section{Competing interests}

The authors declare that they have no competing interests.

\section{Publisher's Note}

Springer Nature remains neutral with regard to jurisdictional claims in published maps and institutional affiliations.

\section{Author details}

${ }^{1}$ Faculdade de Ciências da Nutrição e Alimentação da Universidade do Porto Rua Dr. Roberto Frias, 4200-465 Porto, Portugal. ${ }^{2}$ I3S-Instituto de Investigação e Inovação em Saúde, R. Alfredo Allen, 4200-135 Porto, Portugal. ${ }^{3}$ UISPA, LAETA-INEGI, Faculdade de Engenharia, Universidade do Porto, Porto, Portugal. " EPIUnit, Instituto de Saúde Pública, Universidade do Porto, Rua das Taipas, n 135, 4050-600 Porto, Portugal. ${ }^{5}$ Centro de Investigação em Atividade Física, Saúde e Lazer, Universidade do Porto, R. Dr. Plácido da Costa 91, 4200-450 Porto, Portugal. ${ }^{6}$ CINTESIS - Centre for Health Technology and Services Research, Rua Dr. Plácido da Costa, 4200-450 Porto, Portugal.

\section{Received: 21 April 2017 Accepted: 16 October 2017}

\section{Published online: 31 October 2017}

\section{References}

1. Cashman KD, Dowling KG, Skrabakova Z, Gonzalez-Gross M, Valtuena J, De Henauw S, et al. Vitamin D deficiency in Europe: pandemic? Am J Clin Nutr. 2016;103:1033-44.

2. Holick MF. Vitamin D deficiency. N Engl J Med. 2007;357:266-81

3. Spiro A, Buttriss JL. Vitamin D: an overview of vitamin D status and intake in Europe. Nutr Bull. 2014;39:322-50.

4. Holick MF, Binkley NC, Bischoff-Ferrari HA, Gordon CM, Hanley DA, Heaney $\mathrm{RP}$, et al. Evaluation, treatment, and prevention of vitamin D deficiency: an Endocrine Society clinical practice guideline. J Clin Endocrinol Metab. 2011;96:1911-30

5. Janssen HC, Samson MM, Verhaa HJ. Vitamin D deficiency, muscle function, and falls in elderly people. Am J Clin Nutr. 2002;75:611-5.

6. Sommer I, Griebler U, Kien C, Auer S, Klerings I, Hammer R, et al. Vitamin D deficiency as a risk factor for dementia: a systematic review and metaanalysis. BMC Geriatr. 2017;17:16.

7. Kositsawat J, Geraci SA. Screening for vitamin D deficiency in the elderly. J Miss State Med Assoc. 2010;51:7-10.

8. Chen TC, Lu Z, Holick MF. Photobiology of Vitamin D; 2010. p. 35-60.

9. Holick MF. Nutrition and health-vitamin D physiology, molecular biology, and clinical applications. 2nd ed. Boston: Humana Press; 2010.

10. European Commission. New data on vitamin D from the ODIN Project.Foodbased solutions for optimal vitamin D nutrition and health through the life cycle. Short summary of the symposium of 3rd of march 2016 in Brussels. 2016.

11. Webb AR, Holick MF. Influence of season and latitude on the Cutaneous synthesis of vitamin D exposure to winter sunlight in Boston and Edmonton will not promote vitamin D3 synthesis in human skin. J Clin Endocrinol Metab. 1988;67:373-8.
12. Santos A. Efeitos pleiotrópicos da vitamina D. Efeitos na saúde óssea e cardiovascular Associação Portuguesa de Nutrição Entérica e Parentérica. 2011;1:25.

13. Bandeira F, Griz L, Dreyer P, Eufrazino C, Bandeira C, Freese E. Vitamin D deficiency a global perspective. Arq Bras Endocrinol Metab. 2006;50:640-6.

14. World Health Organization, World Meteorological Organization, United Nations Environment Programme, International Commission on Non-lonizing Radiation Protection. Global solar UV index - a practical guide. 2002.

15. Webb AR. Who, what, where and when-influences on cutaneous vitamin D synthesis. Prog Biophys Mol Biol. 2006;92:17-25.

16. Brustad M, Alsaker E, Engelsen $\mathrm{O}$, Aksnes L, Lund E. Vitamin D status of middle-aged women at 65-71 degrees $\mathrm{N}$ in relation to dietary intake and exposure to ultraviolet radiation. Public Health Nutr. 2004;7:327-35.

17. Prodam F, Zanetta S, Ricotti R, Marolda A, Giglione E, Monzani A, et al. Influence of ultraviolet radiation on the association between 25-Hydroxy vitamin $\mathrm{D}$ levels and cardiovascular risk factors in obesity. J Pediatr. 2016;171:83-9. e1

18. Mesquita KC, Igreja AC, Costa IMC. Ultraviolet index: a light in atopic dermatitis and vitamin D research? An Bras Dermatol. 2016;91:34-9.

19. Klassen KM, Fairley CK, Kimlin MG, Kelly M, Read TR, Broom J, et al. Ultraviolet index and location are important determinants of vitamin D status in people with human immunodeficiency virus. Photochem Photobiol. 2015;91:431-7.

20. Amaral TF, Santos A, Guerra RS, Sousa AS, Alvares L, Valdiviesso R, et al. Nutritional strategies facing an older demographic: the nutrition UP 65 study protocol. J Med Internet Res. 2016;5:e184.

21. Navarro Valverde C, Quesada-Gomez J. Vitamin D deficiency in Spain. Reality or myth? Rev Osteoporos Metab Miner. 2014;6(Suppl 1):S5-10.

22. Navarro-Martinez R, Fernandez-Garrido J, Buigues C, Martinez-Martinez M, Cantero-Diaz L, Santamaria-Carrillo $Y$, et al. Serum vitamin D and functional impairment in octogenarian women. Appl Nurs Res. 2016;30:e10-4.

23. Rodríguez Sangrador M, Beltrán de Miguel B, Quintanilla Murillas L, Cuadrado Vives C, Moreiras Tuny O. Contribución de la dieta y la exposición solar al estatus nutricional de vitamina D en españolas de edad avanzada; Estudio de los Cinco Países (Proyecto OPTIFORD). Nutr Hosp. 2008;23:567-76.

24. Isaia G, Giorgino R, Rini GB, Bevilacqua M, Maugeri D, Adami S. Prevalence of hypovitaminosis D in elderly women in Italy: clinical consequences and risk factors [journal article]. Osteoporos Int. 2003;14:577-82.

25. Houston KD, Cesari M, Ferrucci L, Cherubini A, Maggio D, Bartali B, et al. Association between vitamin D status and physical performance: the InCHIANTI study. J Gerontol A. 2007;62:440-6.

26. Mosekilde L, Vitamin D. And the elderly. Clin Endocrinol. 2005;62:265-81.

27. Lips P. Vitamin D deficiency and secondary hyperparathyroidism in the elderly: consequences for bone loss and fractures and therapeutic implications. Endocr Rev. 2001;22:477-501.

28. Greer RM, Portelli SL, Hung BS, Cleghorn GJ, McMahon SK, Batch JA, et al. Serum vitamin D levels are lower in Australian children and adolescents with type 1 diabetes than in children without diabetes. Pediatr Diabetes. 2013;14:31-41.

29. Instituto Nacional de Estatística. Censos 2011 Resultados Definitivos -Portugal. 2012

30. German Meteorological Service (DWD). UV index forecasting. 2015.

31. Fitzpatrick T. Soleil et peau [Sun and skin]. J Med Esthet. 1975:33-4.

32. Guerreiro M, Silva AP, Botelho MA, Leitão O, Castro-Caldas A, Garcia C. Adaptação à população portuguesa da tradução do Mini Mental State Examination (MMSE). Rev Port Neurol. 1994;1:9-10.

33. Craig CLMA, Sjöström M, Bauman AE, Booth ML, Ainsworth BE. International physical activity questionnaire: 12-country reliability and validity. Med Sci Sports Exerc. 2003;35:1381-95.

34. Fried LPTC, Walston J, Newman AB, Hirsch C, Gottdiener J, Seeman T, Tracy R, Kop WJ, Burke G, McBurnie MA. Frailty in older adults: evidence for a phenotype. J Gerontol A. 2001;56:146-56.

35. Afonso L, Moreira T, Oliveira A. Índices de adesão ao padrão alimentar mediterrânico - a base metodológica para estudar a sua relação com a saúde. Rev Fact Risco. 2014;31:48-55.

36. Martinez-Gonzalez MA, Garcia-Arellano A, Toledo E, Salas-Salvado J, Buil-Cosiales P, Corella D, et al. A 14-item Mediterranean diet assessment tool and obesity indexes among high-risk subjects: the PREDIMED trial. PLoS One. 2012;7:e43134. 
37. Vintém J. Inquéritos Nacionais de Saúde: auto-percepção do estado de saúde: uma análise em torno da questão de género e da escolaridade. Rev Port Saúde Pública. 2008;

38. Nestlé Nutrition Institute. Mini Nutritional Assessment. MNA. Português. http://www.mna-elderly.com/forms/MNA_portuguese.pdf. Accessed 10 Jan 2017.

39. Kaiser MJ, Bauer JM, Ramsch C, Uter W, Guigoz Y, Cederholm T, et al. Validation of the mini nutritional assessment short-form (MNA ${ }^{\circledR}$-SF): a practical tool for identification of nutritional status. J Nutr Health Aging. 2009:13:782-8

40. Stewart A, Marfell-Jones M, Olds T, H. R. International standards for anthropometric assessment. Australia: International Society for the Advancement of Kinanthropometry; 2011.

41. World Health Organization. BMI classification. (2017). http://www.euro.who. int/en/health-topics/diseaseprevention/nutrition/a-healthy-lifestyle/bodymass-index-bmi. Accessed 7 Jan 2017.

42. Roche Diagnostics Cobas. Vitamin D total. 25-Hidroxivitamina Dl.ms_ 05894913190.V7.0. 2015.

43. Jones G. Pharmacokinetics of vitamin D toxicity. Am J Clin Nutr. 2008;88:582S-6S

44. Vieth R. Vitamin D supplementation, 25-hydroxyvitamin D concentrations and safety. Am J Clin Nutr. 1999;69:842-56.

45. Kasahara AK, Ravinder JS, Andrew N. Vitamin D (25OHD) serum seasonality in the United States. PLoS One. 2013;8.

46. Hine TJ, Roberts NB. Seasonal variation in serum 25-Hydroxy vitamin D3 does not affect 1,25-Dihydroxy vitamin D. Ann Clin Biochem. 1994;31:31-4.

47. US Department of Health and Human Services and US Department of Agriculture. 2015-2020 dietary guidelines for Americans. 8th ed; 2015.

48. Brouwer-Brolsma EM, Vaes AMM, Zwaluw NL, Wijngaarden JP, Swart KM, Ham AC, et al. Relative importance of summer sun exposure, vitamin D intake, and genes to vitamin D status in Dutch older adults: the B-proof study. J Steroid Biochem Mol Biol. 2015;164

49. Millen AE, Wactawski-Wende J, Pettinger M, Melamed ML, Tylavsky FA, Liu S, et al. Predictors of serum 25-hydroxyvitamin D concentrations among postmenopausal women: the Women's Health Initiative calcium plus vitamin D clinical trial. Am J Clin Nutr. 2010;91:1324-35.

50. World Health Organization, International Agency For Research On Cancer. Vitamin D and cancer / a report of the IARC working group on vitamin D. 2008.

51. Landau SE, SE. Handbook of statistical analyses using SPSS. United States of America: Chapman \& Hall/CRC; 2003.

52. Mithal A, Wahl DA, Bonjour JP, Burckhardt P, Dawson-Hughes B, Eisman JA, et al. Global vitamin D status and determinants of hypovitaminosis D. Osteoporos Int. 2009;20:1807-20.

53. Brouwer-Brolsma EM, Berendsen AAM, Vaes MMA, Dullemeijer C, de Groot LC, Feskens EJ. Collection and analysis of published scientific information as preparatory work for the setting of dietary reference values for vitamin D. EFSA supporting publication 2016:EN-766.2016:1-171.

54. Tran B, Armstrong BK, McGeechan K, Ebeling PR, English DR, Kimlin MG, et al. Predicting vitamin D deficiency in older Australian adults. Clin Endocrinol. 2013;79:631-40

55. Wanner M, Richard A, Martin B, Linseisen J, Rohrmann S. Associations between objective and self-reported physical activity and vitamin D serum levels in the US population. Cancer Causes Control. 2015;26:881-91.

56. Malik R. Vitamin D and secondary hyperparathyroidism in the institutionalized elderly. J Nutr Elder. 2008;26:119-38.

57. Papapetrou PD, Triantafyllopoulou M, Korakovouni A. Severe vitamin D deficiency in the institutionalized elderly. J Endocrinol Investig. 2008;31:784-7.

58. Holick MF. Sunlight and vitamin D for bone health and prevention of autoimmune diseases, cancers, and cardiovascular disease. Am J Clin Nutr. 2004;80(Suppl 6):1678-88.

59. O'Neill CM, Kazantzidis A, Ryan MJ, Barber N, Sempos CT, Durazo-Arvizu RA, et al. Seasonal changes in vitamin D-effective UVB availability in Europe and associations with population serum 25-Hydroxyvitamin D. Nutrients. 2016;8

60. Papapetrou PD, Triantaphyllopoulou M, Karga H, Zagarelos P, Aloumanis K, Kostakioti $E$, et al. Vitamin D deficiency in the elderly in Athens, Greece. J Bone Miner Metab. 2007;25:198-203.

61. Papadakis G, Keramidas I, Kakava K, Pappa T, Villiotou V, Triantafillou E, et al. Seasonal variation of serum vitamin $D$ among Greek female patients with osteoporosis. In vivo. 2015;29:409-14.

62. Santos AM, Fernandes V, Garcia FM. Carência de Vitamina D numa População Hospitalar: Uma Fotografia pela Perspetiva Laboratorial. Acta Medica Port. 2015;28:726-34.
63. Nair R, Maseeh A. Vitamin D: the "sunshine" vitamin. J Pharmacol Pharmacother. 2012;3:118-26.

64. Seckmeyer G, Schrempf M, Wieczorek A, Riechelmann S, Graw K, Seckmeyer S, et al. A novel method to calculate solar UV exposure relevant to vitamin D production in humans. Photochem Photobiol. 2013;89:974-83.

65. Maeda SS, Saraiva GL, Hayashi LF, Cendoroglo MS, Ramos LR, Correa Mde $P$, et al. Seasonal variation in the serum 25-hydroxyvitamin D levels of young and elderly active and inactive adults in Sao Paulo, Brazil: the Sao PAulo vitamin D evaluation study (SPADES). Dermatoendocrinol. 2013;5:211-7.

66. Brot C, Vestergaard P, Kolthoff N, Gram J, Hermann AP, Sørensen OH. Vitamin D status and its adequacy in healthy Danish perimenopausal women: relationships to dietary intake, sun exposure and serum parathyroid hormone. Br J Nutr. 2001;86:S97-S103.

67. Kimlin M, Harrison S, Nowak M, Moore M, Brodie A, Lang C. Does a high UV environment ensure adequate vitamin D status? J Photochem Photobiol B. 2007:89:139-47.

68. Van der Wielen RP, Löwik MR, van den Berg H, de Groot LC, Haller J, Moreiras $\mathrm{O}$, et al. Serum vitamin D concentrations among elderly people in Europe. Lancet 1995; 346:207-210.

69. Lips P. Worldwide status of vitamin D nutrition. J Steroid Biochem Mol Biol. 2010;121:297-300.

70. Naugler C, Zhang J, Henne D, Woods P, Hemmelgarn BR. Association of vitamin D status with socio-demographic factors in Calgary, Alberta: an ecological study using census Canada data. BMC Public Health. 2013;13:316.

71. Shinkov A, Borissova A-M, Dakovska L, Vlahov J, Kassabova L, Svinarov D, et al. Differences in the prevalence of vitamin D deficiency and hip fractures in nursing home residents and independently living elderly. Arch Endocrinol Metab. 2016;60:217-22.

72. Bertrand KA, Giovannucci E, Liu Y, Malspeis S, Eliassen AH, Wu K, et al. Determinants of plasma 25-hydroxyvitamin $\mathrm{D}$ and development of prediction models in three U.S. cohorts. Br J Nutr. 2012;108:1889-96.

73. van den Heuvel EG, van Schoor N, de Jongh RT, Visser M, Lips P. Crosssectional study on different characteristics of physical activity as determinants of vitamin D status; inadequate in half of the population. Eur J Clin Nutr 2013; 67:360-365.

74. Jolliffe DA, Hanifa Y, Witt KD, Venton TR, Rowe M, Timms PM, et al. Environmental and genetic determinants of vitamin D status among older adults in London. UK J Steroid Biochem Mol Biol. 2016;164:30-5.

75. Zhang R, Naughton DP. Vitamin D in health and disease: current perspectives. Nutr J. 2010;9:65.

76. Burgaz A, Åkesson A, Oster A, Michaelsson K, Wolk A. Associations of diet, supplement use, and ultraviolet $B$ radiationexposure with vitamin D status in Swedish women during winter. Am J Clin Nutr. 2007;86:1399-404.

77. van der Meer IM, Boeke AJ, Lips P, Grootjans-Geerts I, Wuister JD, Deville $W L$, et al. Fatty fish and supplements are the greatest modifiable contributors to the serum 25-hydroxyvitamin D concentration in a multiethnic population. Clin Endocrinol 2008; 68:466-472.

78. van der Wielen RP, Löwik MR, van den Berg H, de Groot LC, Haller J, Moreiras $\mathrm{O}$, et al. Serum vitamin D concentrations among elderly people in Europe. Lancet 1995; 346.

79. Webb AR, Engelsen O. Calculated ultraviolet exposure levels for a healthy vitamin D status. Photochem Photobiol. 2006;82:1697-703.

80. Grant W, Holick MF. Benefits and requirements of vitamin D for optimal health: a review. Altern Med Rev. 2005;10:94-111.

81. Millen AE, Bodnar LM. Vitamin D assessment in population-based studies: a review of the issues. Am J Clin Nutr. 2008;87:1102-5.

82. Durvasula S, Gies P, Mason RS, Chen JS, Henderson S, Seibel MJ, et al. Vitamin $D$ response of older people in residential aged care to sunlight-derived ultraviolet radiation. Arch Osteoporos. 2014;9:197.

83. Reid IR, Gallagher DJA, Bosworth J. Prophylaxis against vitamin D deficiency in the elderly by regular runlight exposure. Age Ageing. 1986;15:35-40.

84. Maxwell JD. Seasonal variation in vitamin D. Proc Nutr Soc. 2007;53:533-43.

85. Fioletov VE, MCArthur LJ, Mathews TW, Marrett L. On the relationship between erythemal and vitamin D action spectrum weighted ultraviolet radiation. J Photochem Photobiol B. 2009;95:9-16.

86. Engelsen $\mathrm{O}$. The relationship between ultraviolet radiation exposure and vitamin D status. Nutrients. 2010;2:482-95. 